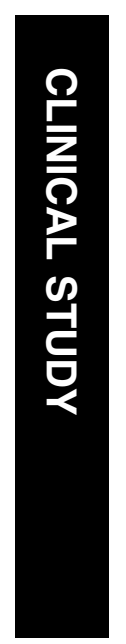

\section{Attitudes and behaviour of ophthalmologists to smoking cessation}

${ }^{1}$ Department of Public Health, Bury Primary

Care Trust, UK

${ }^{2}$ Department of Ophthalmology, Bolton Hospitals NHS Trust, Royal Bolton Hospital, Farnworth, Bolton, Lancs, UK

${ }^{3}$ Department of Public Health, Wellington School of Medicine and Health Sciences, University of Otago, Wellington, New Zealand

${ }^{4}$ Evidence for Population Health Unit, University of Manchester, Manchester, UK

${ }^{5}$ Department of Public Health, Bolton Primary Care Trust, Bolton, UK

Correspondence: SP Kelly Bolton Hospitals NHS Trust, Royal Bolton Hospital, Farnworth, Bolton, Lancs BL4 OJR, UK

Tel: + 441204390694 ;

Fax: +44 1204390554

E-mail:

simon.kelly@rbh.nhs.uk

Received: 21 December 2005

Accepted in revised form:

28 July 2006

Published online:

29 September 2006

\begin{abstract}
Aims Growing evidence suggests a causal association between smoking and eye disease. This study explores the current beliefs and practice among UK consultant ophthalmologists towards delivering smoking cessation advice to eye clinic attenders.
\end{abstract}

Methods A cross-sectional survey using a postal questionnaire of all UK NHS hospital based consultant ophthalmologists was conducted. The questionnaire explored whether: ophthalmologists identify the smoking status of their patients, advise about the increased risk of eye diseases among smokers, and deliver smoking cessation advice. The availability of departmental smoking cessation resources was also ascertained.

Results The response rate was 55\% (485/886).

Of the responders $79 \%$ were males. Only $35 \%$ of responders asked about smoking status every time or most times for new patients and $5 \%$ for follow-up patients. In all, $40 \%$ claimed to always or usually advise patients to quit smoking and $61 \%$ claimed to always or usually mention eye disease as a reason to quit. Only $14 \%$ assessed motivation to quit and $22 \%$ provided advice and assistance about how to stop smoking to smokers who wished to quit. Female ophthalmologists were more likely to undertake most aspects of smoking assessment and intervention. Only $18 \%$ of responders stated that their departments provide information about smoking for patients and $6 \%$ stated that support is available for patients wanting to quit smoking. Conclusion The assessment of smoking status and provision of targeted support for smokers to quit could be substantially improved in UK ophthalmology departments. There is a need to introduce smoking cessation support into routine ophthalmic practice and provide the resources to support this. Eye (2008) 22, 246-250; doi:10.1038/sj.eye.6702592; published online 29 September 2006
A Sahu ${ }^{1,2}$, R Edwards 3 , RA Harrison ${ }^{4,5}$, J Thornton ${ }^{4}$ and SP Kelly ${ }^{2}$

Keywords: physician; smoking; smoking cessation; survey; ophthalmology; clinic

\section{Introduction}

Smoking can cause eye diseases such as cataract ${ }^{1}$ and age-related macular degeneration $(\mathrm{AMD})^{2}$ that may lead to blindness. Other eye diseases that may be associated with smoking include thyroid eye disease, diabetic retinopathy and glaucoma. ${ }^{3}$ While the link between smoking and eye disorders and blindness may be known to ophthalmologists, it is uncertain whether ophthalmologists warn their patients of this risk or indeed question the smoking status of their patients. In a survey of patients attending eye and outpatient clinics, we reported a lack of knowledge about the association between smoking and eye disease. ${ }^{4}$ Evidence from New Zealand suggests that knowledge about the link between smoking and blindness may stimulate smokers to contact stop smoking services. ${ }^{5}$

Quitting smoking can be difficult for many smokers. Quit rates can be increased by brief counselling/advice from doctors and other health care professionals and the prescription of nicotine replacement therapy or other pharmaceutical treatments. ${ }^{6}$ Simple advice to quit from health care professionals can increase quit rates.

In the UK, the (former) Health Education Authority (HEA) published guidance on smoking cessation for various groups of health professionals in $1998^{6}$ and in 2000 included specific recommendations for hospital patients. ${ }^{8}$ Currently evidence exists for the effectiveness of smoking cessation advice and support delivered by GPs, dentists, nurses, midwives, and pharmacists. There is no such evidence for eyecare staff including ophthalmologists, and there is little knowledge about the practice of 
ophthalmic practitioners with respect to smoking cessation in the UK. In the USA, Gordon et $a l^{9}$ found that while ophthalmologists consider it appropriate to assist smokers with smoking cessation activities, few actually assist smokers in real life clinical practice. The barriers included time constraints, worries about 'negative patient reactions' and 'loss of patients from practice'. 9

We undertook a cross-sectional survey of UK ophthalmologists to assess their current practice regarding the assessment of patient smoking status and providing smoking cessation advice and support. We also set out to examine the proportion of ophthalmologists who warn smokers that smoking is a risk factor for eye disease.

\section{Materials and methods}

\section{Participants and sampling}

A cross-sectional postal survey of UK, hospital-based, consultant ophthalmologists was performed. All consultants were identified from the Royal College of Ophthalmologists' mailing list of registered consultant practitioners. One consultant was excluded as he was involved in the development of the questionnaire giving a total of 905 consultants.

\section{Data collection}

A self-completion questionnaire was developed following a literature review and discussions with colleagues and experts in the field. Some of the questions were adapted from a previous study about the prescribing of Nicotine Replacement Therapy in pregnancy by GPs. ${ }^{10}$ Data collected included: sex, the number of years in post as a consultant ophthalmologist, and current practice towards recording smoking status and delivering smoking cessation advice. Responders were asked to specify their current practice based on a five-point Likert scale 'every time', 'most times', 'sometimes', 'rarely' and 'never'. The questions related to smoking cessation were based on the '5As' approach formulated by the US Public Health Service for the clinical management of tobacco use recommending practitioners ask (about smoking status), advise (advise smokers to quit), assess (a smoker's motivation/interest in quitting), assist (the quit attempt), and arrange (follow-up). ${ }^{11}$ Other questions were framed to address the HEA recommendations for smoking cessation in hospital trusts, for example, recording the smoking status for patients, where practicable, and that current smokers attending hospital should receive opportunistic advice from a clinician similar to that described for GPs and the advice should be recorded in the notes. ${ }^{8}$
The questionnaire was field tested among ophthalmic trainees. Questionnaires with an accompanying covering letter and a prepaid return envelope were posted to all UK-based consultant ophthalmologists. One reminder letter was sent three weeks later if required and then a reminder letter plus questionnaire were sent 3 weeks after that to nonresponders.

\section{Statistical analysis}

Data were analysed using the computer statistical packages StatsDirect version 2.3.7 (www.statsdirect.com, Sale, Cheshire, UK) and Stata version 9.0 (www.stata.com, StataCorp, College Station, TX, USA). Nonresponse for missing data in questionnaires was managed by excluding them from the analysis and percentages are given for those who responded to each question. Proportions were compared using $\chi^{2}$-tests and $\chi^{2}$-test for trend. Adjusted odds ratios were calculated using Maentel-Haenszel stratified analysis.

\section{Ethical issues}

An ethics approval waiver was granted by Greater Manchester Research and Ethics Committee.

\section{Results}

\section{Profile of responders}

In total, 905 questionnaires were mailed out, nine were returned by the Royal Mail marked 'no longer at this address'. Another 10 were excluded as they were from consultants who were mainly or wholly practising in paediatric ophthalmology, giving a denominator of 886 . A total of 485 out of 886 potential responders replied: a response rate of $54.7 \%$. In all, $78.9 \%$ were male (374/474, with missing data on sex in 11). Most, 66.2\% (313/473, with missing data on years of consultant service in 12), had more than 5 years of consultant service, mean 10.6 years (SD 7.1, median 10 years). A comparison of the responders and nonresponders by sex showed a similar gender profile of responders and nonresponders. On 1st January $2005,83 \%$ of all consultant ophthalmologists working in the NHS were male. ${ }^{12}$

\section{Assessment of smoking status and delivery of smoking cessation advice}

Table 1 describes the results for asking about smoking and providing smoking cessation advice and support. Only $35 \%$ of respondents always or usually asked new patients about smoking and very few (5\%) did so for follow-up patients. Of those who asked about smoking 
Table 1 Consultant ophthalmologists' current practice for delivering smoking cessation interventions

\begin{tabular}{lcccc}
\hline & $\begin{array}{c}\text { No. of } \\
\text { responders }\end{array}$ & $\begin{array}{c}\text { Every/most times } \\
\mathrm{N}(\%) 95 \% C I\end{array}$ & $\begin{array}{c}\text { Sometimes } \\
\mathrm{N}(\%) 95 \% \text { CI }\end{array}$ & $\begin{array}{c}\text { Rarely/never } \\
\mathrm{N}(\%) 95 \% \text { CI }\end{array}$ \\
\hline Ask new patients whether they smoke & 485 & $171(35.3)$ & $229(47.2)$ & $85(17.5)$ \\
& & $31.0-40.0$ & $42.7-51.8$ & $14.2-21.2$ \\
Ask follow-up patients whether they smoke & 482 & $24(5.0)$ & $218(45.2)$ & $240(49.8)$ \\
& & $3.2-7.3$ & $40.7-49.8$ & $45.2-54.3$ \\
& 480 & $191(39.8)$ & $209(43.5)$ & $80(16.7)$ \\
Advise patients to stop smoking & & $35.1-44.0$ & $39.1-48.1$ & $13.4-20.3$ \\
& 479 & $69(14.4)$ & $131(27.3)$ & $279(58.2)$ \\
Assess a patient's motivation to stop smoking & & $11.4-17.9$ & $23.4-31.6$ & $53.7-62.7$ \\
& 471 & $102(21.7)$ & $87(18.5)$ & $282(59.9)$ \\
Offer advice and assistance to smokers who say they want to stop & & $18.0-25.7$ & $15.1-22.3$ & $55.3-64.3$ \\
& 415 & $253(61.0)$ & $121(29.2)$ & $41(9.9)$ \\
Mention the risk of eye disease as a reason to stop smoking & & $56.1-65.7$ & $24.8-33.8$ & $7.2-13.2$ \\
\end{tabular}

status, the commonest specific enquiries by responders were whether a patient smokes $(95.1 \%, 95 \%$ CI: $92.5-$ $81.2 \%)$ and how much they smoke $(81.2 \%, 95 \%$

CI: 77.1-84.9).

Most responders reported that when they did ask about smoking status of new patients $(85.5 \%, 95 \%$ CI: $81.9-88.6 \%)$ and follow-up patients $(76.5 \%, 95 \%$ CI: 71.9-80.6\%), this was recorded in the case notes. Compared with males, female consultants were more likely to report that smoking status was recorded in new (92 vs $82 \%, P=0.02$ ) and follow-up patients (88 vs $70 \%$, $P=0.001$ ). Consultants who had qualified for 5 years or fewer were more likely to report that smoking status was reported in the notes compared with respondents with over 5 years as a consultant (new patients 87 vs $82 \%$, $P=0.13$; follow-up patients 80 vs $71 \%, P=0.05$ ).

In contradiction to the low proportion asking about smoking status, $40 \%$ of all respondents claimed to always or usually advise their patients to quit smoking during consultations. However, only $14 \%$ of respondents mostly or always assessed motivation to quit and $22 \%$ provided advice and assistance about how to stop smoking to smokers stating they wished to quit. Of those who stated they ever advised their patients to quit, $61 \%$ claimed to always or usually mention eye disease as a reason to quit smoking.

Ophthalmologists who usually asked about smoking status were more likely to advise their patients to quit. The proportion who most or every time advised patients to quit increased from $18 \%$ among those who rarely asked about smoking status, to $31 \%$ among those who sometimes asked about smoking and $62 \%$ among those who always or usually asked about smoking ( $\chi^{2}$-test for trend $P<0.001)$. Similarly, the proportion who usually or always assessed motivation to quit varied from $1 \%$ among those who rarely gave quit advice, to $7 \%$ for those who sometimes gave quit advice and $27 \%$ for those who usually or always gave quit advice ( $\chi^{2}$-test for trend,
$P<0.001)$. The equivalent figures for always or usually giving advice and assistance about quitting were 3,17 , and $34 \%\left(\chi^{2}\right.$-test for trend, $\left.P<0.001\right)$.

Table 2 shows a comparison of practice in relation to smoking assessment and providing smoking cessation support by sex and years as a consultant. Female ophthalmologists and those with less than 5 years as a consultant were more likely to practice regularly most aspects of smoking assessment and cessation support, although the confidence limits for the adjusted odds ratios were wide and hence the differences between the sexes were not always statistically significant.

\section{Information/support for smokers wishing to quit}

Consultants were asked to describe the form of quitting support delivered if they did give advice to smokers to quit. Of these, few give patients leaflets about how to stop smoking $(4.0 \%)$ or smoking and blindness $(5.0 \%)$, but most do refer to the GP or Primary Care services (66.6\%). A few stated that they referred smokers to specialist smoking cessation services either in the hospital $(14.6 \%)$ or community $(10.3 \%)$.

Ophthalmologists were asked if their department provided any information about smoking for patients. Almost half of the responders $(227 / 480,47 \%)$ said none was provided. Only $18 \%$ of responders stated that their departments did provide information about smoking for patients, the remainder were uncertain. Similarly, $64 \%$ (305/479) of responders stated that their department did not provide any cessation support for patients, 31\% (146/ 479) were unsure and only $6 \%(28 / 479)$ stated that support to quit was available in their setting. The forms of support described as available included: educational resources (eg leaflets) about the general hazards of smoking ( $n=63,69 \%$ ), educational resources (eg leaflets) about smoking and blindness $(n=34,39 \%)$, a specialist smoking cessation service in the hospital $(n=40,44 \%)$, 
Table 2 A comparison of current practice towards delivering smoking cessation interventions by sex and years as a consultant ophthalmologist

\begin{tabular}{|c|c|c|c|c|c|}
\hline Practice & $\begin{array}{c}\text { Crude OR } \\
\text { females vs } \\
\text { males }(95 \% \text { CI) }\end{array}$ & Adjusted & $O R^{\mathrm{a}}$ & $\begin{array}{c}\text { Crude } \\
\text { OR } \leq 5 \text { years } \\
\text { service vs }>5 \text { years } \\
\text { service }(95 \% \text { CI })\end{array}$ & $\begin{array}{c}\text { Adjusted } \\
\mathrm{OR}^{\mathrm{b}}\end{array}$ \\
\hline Record new patients' smoking status & $2.5(1.2-5.4)$ & $\begin{array}{l}\leq 5 \text { years } \\
>5 \text { years }\end{array}$ & $\begin{array}{l}1.7(0.5-5.3) \\
4.2(1.2-14.1)\end{array}$ & $1.5(0.9-2.7)$ & $1.4(0.8-2.5)$ \\
\hline Record follow-up patents' smoking status & $3.1(1.5-6.1)$ & $\begin{array}{l}\leq 5 \text { years } \\
>5 \text { years }\end{array}$ & $\begin{array}{l}1.8(0.7-4.8) \\
5.4(1.8-16.1)\end{array}$ & $1.6(1.0-2.7)$ & $1.5(0.9-2.4)$ \\
\hline $\begin{array}{l}\text { Usually or always ask new patients about } \\
\text { smoking }\end{array}$ & $1.8(1.2-2.9)$ & & $1.8(1.1-2.8)$ & $1.5(1.0-2.2)$ & $1.4(0.9-2.1)$ \\
\hline $\begin{array}{l}\text { Usually or always ask follow-up patients about } \\
\text { smoking }\end{array}$ & $2.1(0.8-5.0)$ & & $2.0(0.8-5.0)$ & $1.5(0.7-3.6)$ & $1.4(0.6-3.4)$ \\
\hline $\begin{array}{l}\text { Usually or always advise patients to stop } \\
\text { smoking }\end{array}$ & $1.5(1.0-2.4)$ & & $1.4(0.9-2.2)$ & $1.7(1.1-2.5)$ & $1.6(1.1-2.3)$ \\
\hline $\begin{array}{l}\text { Usually or always assess patient's motivation } \\
\text { to stop }\end{array}$ & $1.6(0.9-2.9)$ & & $1.6(0.9-2.9)$ & $1.0(0.6-1.8)$ & $1.0(0.6-1.7)$ \\
\hline $\begin{array}{l}\text { Usually or always offer advice/assistance } \\
\text { to those who want to stop }\end{array}$ & $1.8(1.1-2.9)$ & $\begin{array}{l}\leq 5 \text { years } \\
>5 \text { years }\end{array}$ & $\begin{array}{l}1.0(0.4-2.2) \\
2.0(1.4-5.2)\end{array}$ & $1.1(0.7-1.8)$ & $1.1(0.7-1.7)$ \\
\hline $\begin{array}{l}\text { Mention the risk of eye disease as a reason } \\
\text { to stop smoking }\end{array}$ & $2.1(1.2-3.5)$ & & $2.0(1.2-3.4)$ & $1.5(0.9-2.2)$ & $1.3(0.9-2.1)$ \\
\hline
\end{tabular}

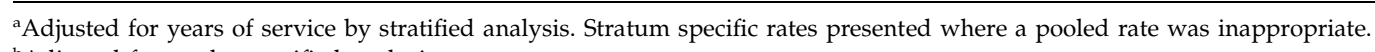

${ }^{\mathrm{b}}$ Adjusted for sex by stratified analysis.

and access to a trained smoking cessation adviser in the ophthalmology clinic $(n=3,3 \%)$.

\section{Importance of assessing smoking status and providing cessation support}

Responders were asked how important it is for ophthalmologists and ophthalmology departments to be able to refer patients directly to smoking cessation services. Most (59.4\%) agreed or strongly agreed that it is important.

Consultants who did not ask about smoking during consultations were asked why they did not do this. Out of $162(33.4 \%)$ who responded, the commonest reasons given were (some gave more than one response): lack of time $(57 \%)$ and forgetting to ask (44\%). However, a small number thought the smoking history was irrelevant $(14 \%)$ and/or asking about smoking was not the role of the ophthalmologist (15\%).

\section{Discussion}

We found that although many ophthalmologists do not assess smoking status regularly, most claim to routinely advise smokers to quit, and most mention the increased risk of eye diseases among smokers as a reason for quitting. Detailed assessment of smoking behaviour and provision of cessation support or referral to specialist services is rare. Few responders stated that their departments provide information about smoking for patients or support for patients wanting to quit smoking. Most responders considered it important for ophthalmologists/ophthalmology departments to be able to directly refer smokers to smoking cessation services.

Strengths of the survey included its novelty as the first study exploring current practice among UK ophthalmologists towards delivering smoking cessation advice to eye clinic attenders. All consultant ophthalmologists were approached to take part. Limitations include the response rate of 55\%, although the responders appeared to be representative at least in experience and gender of all UK ophthalmologists. Also, the study was restricted to consultant ophthalmologists, so the findings may not apply to others in the ophthalmic workforce including those in the community or in Primary Care.

An apparent discrepancy in the results was that a greater proportion of ophthalmologists reported regularly giving advice to quit smoking than recorded smoking status during consultations. This may have been because, for follow-up patients especially, smoking status was assumed to be known from previous consultations so re-enquiry about smoking status was not required.

Subsequent to this study, the Ocular Public Health Group at the Royal College of Ophthalmologists produced guidance on smoking and eye disease for health professionals which is on the College's website: 'Smoking and eye disease' ${ }^{13}$ The college document highlights the importance of delivering smoking 
cessation interventions and the practical applications of the HEA guidance such as brief opportunistic advice and referral to smoking cessation services for smokers who wish to quit. The British Medical Association's Tobacco Control Resource Centre launched an education package on smoking cessation for ophthalmologists in 2006.

Further details at: http:/ / www.doctorsandtobacco.org. A leaflet on smoking and blindness for patients is available from the charity North West Action on Smoking

(www.nwash.co.uk).

We believe that improved smoking cessation support should be provided in routine ophthalmic practice. The commonest reasons given for not asking about smoking by ophthalmologists in this survey were lack of time and forgetting to ask. Such barriers could be overcome by introducing systematic methods and training to prompt the recording of smoking status of patients and providing brief advice to quit. ${ }^{14}$ In addition, smoking cessation support from trained advisers could be made available within clinic settings or on a referral basis. Pilot studies and controlled trials of such interventions should be carried out to explore the effectiveness of different methods of delivery of smoking cessation support in ophthalmic settings.

\section{Acknowledgements}

Endowment and research funds at the Bolton Eye Unit supported this work. We thank the ophthalmologists who completed our survey and the Royal College of Ophthalmologists for access to their mailing list.

\section{References}

1 Kelly SP, Thornton J, Edwards R, Sahu A, Harrison RA. The causal association between tobacco smoking and cataract. J Cataract Refract Surg 2005; 31(12): 2395-2404.
2 Thornton J, Edwards R, Mitchell P, Harrison RA, Buchan I, Kelly SP. Smoking and age-related macular degeneration: a review of association. Eye 2005; 19(9): 935-944.

3 Solberg Y, Rosner M, Belkin M. The association between cigarette smoking and ocular disease. Surv Ophthalmol 1998; 42(6): 535-547.

4 Bidwell G, Sahu A, Edwards R, Harrison RA, Thornton J, Kelly SP. Perceptions of blindness related to smoking: a hospital-based cross-sectional study. Eye 2005; 19(9): 945-948.

5 Wilson N, Hodgen E, Mills J, Wilson G, Field A, Thomson G. Journal article on smoking and blindness prompts significantly more calls to quitline. NZ Med J 2002; 115: 199-200.

6 Raw M, McNeill A, West R. Smoking cessation guidelines for health professionals. Thorax 1998; 53(Suppl 5, Part I): S1-19.

7 Lancaster T, Stead LF. Physician advice for smoking cessation. The Cochrane Database of Systematic Reviews 2004, Issue 4. Art. No.: CD000165. doi: 10.1002/14651858. CD000165.pub2. http://www.updatesoftware.com/ Abstracts/ab000165.htm

8 West R, McNeil A, Raw M. Smoking cessation guidelines for health professionals. An update. Thorax 2000; 55: 987-999.

9 Gordon JS, Andrews JA, Lichtenstein E, Severson HH, Akers L, Williams C. Ophthalmologists' and optometrists attitudes and behaviours regarding tobacco cessation intervention. Tobacco Control 2002; 11: 84-85.

10 Herbert R, Coleman T, Britton J. UK general practitioners' beliefs, attitudes and reported prescribing of nicotine replacement therapy in pregnancy. Nicotine Tobacco Res 2005; 7(4): 541-546.

11 Fiore MC, Bailey WC, Cohen SJ, Dorfman SF, Goldstein MG, Gritz ER et al. Treating Tobacco use and Dependence. Clinical Practice Guidelines. Department of Health and Human Services: Rockville, MD, USA, 2000.

12 Royal College of Ophthalmologists. Medical workforce in the Hospital Eye Service. Royal College of Ophthalmologists: London, UK, 2005.

13 Royal College of Ophthalmologists. Ocular Public Health Group. Smoking and Eye Disease. Royal College of Ophthalmologists: London, UK.

http://www.rcophth.ac.uk/about/public/public-health.

14 Coleman T. Cessation interventions in routine healthcare. BMJ 2004; 13: 328(7440): 631-633. 